\title{
STUDY OF TYPE II DIABETES MELLITUS PATIENTS OF ASYMPTOMATIC HEART DISEASE BY NON- INVASIVE METHOD IN TRIPURA- A HOSPITAL-BASED STUDY
}

\author{
Swapan Sarkar1, Taranga Reang²
}

${ }_{1}^{1}$ Assistant Professor, Department of Medicine, Agartala Government Medical College and GB Pant Hospital, Agartala, Tripura, India. ${ }^{2}$ Assistant Professor, Department of Community Medicine, Agartala Government Medical College and GB Pant Hospital, Agartala, Tripura, India.

\section{ABSTRACT}

\section{BACKGROUND}

Macro-vascular complications of diabetes mellitus remain the major cause of morbidity and mortality in diabetes today. The objectives of this study were-

1. Assessment of magnitude of asymptomatic heart disease among diabetic patients

2. Evaluation of role of treadmill test or echocardiography or both over resting ECG in diagnosis of asymptomatic heart disease in those patients.

\section{MATERIALS AND METHODS}

The study was carried out among 253 type 2 diabetes patients. A pre-tested, pre-designed, structured interview schedule was used for data collection. Systematic random sampling technique was used to select the individual study subject. All the patients were subjected to 12 lead ECG in rest, Tread Mill Test \& Echocardiography to find out any specific and or nonspecific ischaemic changes.

\section{RESULTS}

There were $60.9 \%$ male $\& 39.1 \%$ female patients with sex ratio of $1.5: 1$ and age ranges from 35 to 80 years. There was positive correlation with age of majority of patients with significant effect with asymptomatic heart disease (AHD).

\section{CONCLUSION}

For detection of AHD, TMT and ECHO combined were more effective. Diastolic dysfunction screening test for early detection of AHD in diabetes is very important. There may be some benefit of screening by non-invasive method to diagnose AHD early in diabetes so as to prevent morbidity and mortality as CAD remains single most common cause of death in this population. But most of the patients failed to recognize the classic symptoms of myocardial ischemia.

\section{KEY WORDS}

Type 2 Diabetes Mellitus, Asymptomatic Heart Disease, Diastolic Dysfunction

HOW TO CITE THIS ARTICLE: Sarkar S, Reang T. Study of type II diabetes mellitus patients of asymptomatic heart disease by noninvasive method in Tripura- a hospital-based study. J. Evolution Med. Dent. Sci. 2019;8(08):535-539, DOI: $10.14260 /$ jemds/2019/118

\section{BACKGROUND}

Diabetes mellitus is known to the mankind from time immemorial and the earliest record of diabetes was made 3000 years ago and had been described by physicians of ancient civilizations of the world like Greece, Egypt, India and China (Cahill Jr, 1982). Shaprio LM1 in 1982 described that in diabetes abnormalities cardiac functions are predominantly in diastole, with delayed opening of mitral valve and prolongation of iso-volumic relaxation time. Reduced ejection and abnormal systolic time interval are probably late events. These diastolic abnormalities may be differentiated from those found in occlusive coronary artery disease, where inordinate ventricular relaxation is the principal feature. Few studies $^{2}$ have been published looking at the utility of exercise testing in diabetics suspected having coronary artery diseases.

'Financial or Other Competing Interest': None.

Submission 03-12-2018, Peer Review 10-02-2019,

Acceptance 16-02-2019, Published 25-02-2019.

Corresponding Author:

Dr. Taranga Reang,

Department of Community Medicine,

Agartala Government Medical College \&

GB Pant Hospital, Agartala, Tripura, India.

E-mail: tarangareang@gmail.com

DOI: $10.14260 /$ jemds $/ 2019 / 118$

(c) (i) $(9)$
The objectives of this study were-

1. Assessment of magnitude of asymptomatic heart disease among diabetic patients

2. Evaluation of role of treadmill test or echocardiography or both over resting ECG in diagnosis of asymptomatic heart disease in those patients.

\section{MATERIALS AND METHODS}

The study was carried out in Diabetes and nutrition clinic of Agartala Government Medical College and Govinda Ballabh Pant Hospital, Agartala during $4^{\text {th }}$ December 2007 to $31^{\text {st }}$ March 2010. Sample size of $246 \sim 250$ was calculated using the formula $\mathrm{Z} 1-\alpha / 2^{2} \mathrm{p}(1-\mathrm{p}) / \mathrm{d}^{2}$, assuming prevalence of asymptomatic heart disease in diabetes about $20 \%$, absolute error taken as $5 \%$. The patients having type 2 diabetes mellitus for more than 10 years and age $\geq 35$ years were included in the study. Patients with past history of myocardial infarction, evidence of acute myocardial infarction, suggestive history of ischaemic heart disease, signs of congestive heart failure, history of acute febrile illness, and or acute infection, history of renal and or hepatic impairment, evidence of chronic obstructive pulmonary disease, pregnancy, hypertension and pericardial disease were excluded from the study. A pre-tested pre-designed structured interview schedule was used for data collection. 
Systematic random sampling technique was used to select the individual study subject. All the patients were subjected to a battery of required investigations. All the patients were subjected to 12 lead ECG in rest, Tread Mill test (Bruce protocol) \& Echocardiography to find out any specific and or nonspecific ischaemic changes.

\begin{tabular}{|c|c|}
\hline $\begin{array}{l}\text { Resting ECG: } \\
\text { - } \quad \text { Specific changes ST } \downarrow, \mathrm{ST} \uparrow, \mathrm{Q}, \mathrm{T} \text { Inversion } \\
\text { - } \quad \text { Non-Specific changes } \\
\text { Echo Cardiography: Wall motion at rest } \\
\qquad \mathrm{EF} \text { at rest } \\
\text { Diastolic Dysfunction } \\
\text { - } \quad \text { Both myocardial \& mitral inflow E/A }<1 \\
\text { - } \quad \text { Myocardial E/A }<1 \text {, mitral inflow E/A }>1 \\
\text { - } \quad \text { Myocardial E/A }<1, \text { mitral inflow E/A }>1.5 \\
\text { Systolic Dysfunction } \\
\text { - } \quad \text { Ejection fraction }<40 \% \\
\text { - } \quad \text { End Systolic volume }>70 \mathrm{ml} \\
\text { - } \quad \text { Fractional shortening }<23 \% \\
\text { - } \quad \text { Extensive regional wall motion abnormality }\end{array}$ & $\begin{array}{l}\text { Tread Mill Test } \\
\text { - } \quad \text { Exercise capacity } \\
\text { - } \quad 1 \text { mm ST depression } \\
\text { T- Wave } \\
\text { - } \quad \text { Tall, Symmetrical, Arrow head } \\
\text { - } \quad \text { Inverted, Symmetrical, Arrow head } \\
\text { - } \quad \text { U-WBave inversion }\end{array}$ \\
\hline
\end{tabular}

\section{Statistical Analysis}

All the data and values of the investigations are incorporated in the questioner sheet and analysed statistically using SPSS software 15.0 or Epi info version 6.0 wherever applicable. The descriptive statistics like percentages were calculated. The inferential statistics like Chi square test were applied wherever applicable.

\section{RESULTS}

A total number of 253 patients were selected randomly from Diabetes Nutrition Clinic of Agartala Government Medical College \& GBP hospital, Agartala for the study. There were $60.9 \%$ male \& $39.1 \%$ female patients with sex ratio of $1.5: 1$. One hundred male and 70 female patients have AHD. The participants' age ranges from 35 to 80 years. Majority of patients belonged to age group of 45-54 years which constituting $36.4 \%$ patients. There was positive correlation with age of the majority patients with significant effect with asymptomatic heart disease (AHD). Majority of AHD in female was found in the age group of 45-54 years while majority of AHD in male was found in the age group of 55-63 years. (Table 1)

More than seventy percent (70.4\%) of patients had 10 years duration of diabetes out of which 101 (56.7\%) male and $77(43.3 \%)$ patients. More than twenty seven percent (27.3\%) patients had 11 to 20 years duration, $2 \%$ had duration for 20 to 30 years while $0.4 \%$ had duration for $>30$ years. There was positive correlation and significance of AHD with duration of diabetes. (Table 2)

Nearly thirty five percent $(34.79 \%)$ patients, out of which $55.68 \%$ male and $44.31 \%$ female patients had abnormal ECG finding at rest. Majority of male patients, 21 patients having abnormal ECG finding belong to age group 56-63 years while majority female patients, 14 patients having abnormal ECG at rest belong to 45-54 age group. (Table 3)
Over all almost twenty one percent (20.9\%) patients out of which $56.60 \%$ male \& $43.39 \%$ female have TMT test positive. (Table 4)

More than five percent patients (5.1\%) were having systolic dysfunction (SD). Over all more than twenty three percent $(23.07 \%)$ patients out of which $1.19 \%$ and $3.55 \%$ had systolic dysfunction were also having abnormal ECG changes and diastolic dysfunction (DD) respectively. 131 (51.8\%) patients constituting, 77 male patients \& 54 female patients were having diastolic dysfunction on echocardiography. (Table 5)

In this study ECG, TMT, Echocardiography (DD) test for AHD of all the 253 patients were undertaken. On the basis of these three tests, $32.81 \%$ patients constituting 54 male and 29 female patients did not have any abnormality. Twenty-one (8.30\%) patients constituting 10 male and 11 female patients were having abnormality in all three tests; ECG, TMT and Echocardiography (DD).34(13.44\%) patients constituting 20 male and 14 female patients were having abnormality both in ECG and Echocardiography (DD). Six (2.37\%) patients constituting 3 male and 3 female patients were having abnormality both in ECG and TMT. Twenty (7.91\%) patients constituting 13 male and 7 female patients were having abnormality in TMT and Echocardiography (DD). Twentyseven $(10.67 \%)$ patients constituting 16 male and 11 female patients were having abnormality in ECG and showing TMT and Echocardiography normal. Fifty-six (22.13\%) patients constituting 34 male and 22 female patients were having abnormality in Echocardiography and showing TMT and ECG normal. Six (2.37\%) constituting 4 male and 2 female patients were having abnormality in TMT and showing ECG and Echocardiography normal. Nearly seventy-one (70.71\%) percent of female patients were having AHD whereas 64.94\% male patients were having AHD. (Table 6, Fig. 1, 2 \& 3). 


\begin{tabular}{|c|c|c|c|c|c|}
\hline \multirow{2}{*}{ Age } & \multicolumn{2}{|c|}{ Sex } & \multicolumn{2}{c|}{ AHD } & \multirow{2}{*}{ Total, } \\
\cline { 2 - 6 } & $\begin{array}{c}\text { Male, } \\
\mathbf{N}(\%)\end{array}$ & $\begin{array}{c}\text { Female, } \\
\text { N (\%) }\end{array}$ & $\begin{array}{c}\text { Male, } \\
\text { N (\%) }\end{array}$ & $\begin{array}{c}\text { Female, } \\
\text { N (\%) }\end{array}$ & N (\%) \\
\hline $35-44$ & $33(21.4)$ & $33(33.3)$ & $12(12.0)$ & $20(28.6)$ & $66(26.1)$ \\
\hline $45-54$ & $53(34.4)$ & $39(39.4)$ & $33(33.0)$ & $25(35.7)$ & $92(36.4)$ \\
\hline $55-63$ & $51(33.1)$ & $18(18.2)$ & $41(41.0)$ & $16(22.9)$ & $69(27.3)$ \\
\hline $64-73$ & $15(9.7)$ & $8(8.1)$ & $13(13.0)$ & $8(11.4)$ & $23(9.1)$ \\
\hline$>73$ & $2(1.3)$ & $1(1.0)$ & $1(1.0)$ & $1(1.4)$ & $3(1.2)$ \\
\hline \multirow{2}{*}{ Total } & $\mathbf{1 5 4}$ & $\mathbf{9 9}$ & $\mathbf{1 0 0}$ & $\mathbf{7 0}$ & $\mathbf{2 5 3}$ \\
& $\mathbf{( 1 0 0 . 0 )}$ & $\mathbf{( 1 0 0 . 0 )}$ & $\mathbf{( 1 0 0 . 0 )}$ & $\mathbf{( 1 0 0 . 0 )}$ & $\mathbf{( 1 0 0 . 0 )}$ \\
\hline
\end{tabular}

Table 1. Age Wise Distribution of AHD and Its Correlation Figures in ( ) is percentage out of 253 (Total) column wise. Correlation between Age \& AHD-- $(+0.287)$ and P Value (0.000)

\begin{tabular}{|c|c|c|c|c|}
\hline \multirow{2}{*}{$\begin{array}{c}\text { Duration } \\
\text { (Years) }\end{array}$} & \multicolumn{2}{|c|}{ AHD, N (\%) } & \multirow{2}{*}{$\begin{array}{c}\text { No AHD } \\
\text { N (\%) }\end{array}$} & \multirow{2}{*}{$\begin{array}{c}\text { Total } \\
(\%)\end{array}$} \\
\hline & Male & Female & & \\
\hline 10 & $61(61.0)$ & $51(72.9)$ & $66(79.5)$ & $178(70.4 \%)$ \\
\hline $11-20$ & $36(36.0)$ & $17(24.3)$ & $16(19.3)$ & $69(27.3 \%)$ \\
\hline $21-30$ & $02(2.0)$ & $02(2.8)$ & $1(1.2)$ & $5(2 \%)$ \\
\hline$>30$ & $01(1.0)$ & $0(0.0)$ & $0(0.0)$ & $1(0.4 \%)$ \\
\hline Total & $\begin{array}{c}100 \\
(100.0)\end{array}$ & $\begin{array}{c}70 \\
(100.0)\end{array}$ & $\begin{array}{c}83 \\
(100.0)\end{array}$ & $\begin{array}{c}253 \\
(100.0)\end{array}$ \\
\hline
\end{tabular}

Table 2. Correlation Between Duration \& AHD

\section{Figures in ( ) is percentage of column wise}

orrelation between Duration \& AHD-- $(+0.141)$ and value $0.025)$

\begin{tabular}{|c|c|}
\hline ECG Changes & $\begin{array}{c}\text { Number of Patients } \\
\mathrm{N},(\%)\end{array}$ \\
\hline Anterior Wall Ischemia & $28(31.82)$ \\
\hline Lateral Wall Ischemia & $08(9.09)$ \\
\hline Inferior Wall Ischemia & $08(9.09)$ \\
\hline RBBB & $12(13.64)$ \\
\hline LBBB & $02(2.27)$ \\
\hline VPC & $06(6.82)$ \\
\hline Bradycardia with Non-Progressive R & $04(4.54)$ \\
\hline Non-Specific ST-T & $20(22.73)$ \\
\hline Total & $88(100)$ \\
\hline \multicolumn{2}{|c|}{ Table 3. Distribution of Abnormal ECG Changes } \\
\hline ires in () is percentage of column $\mathrm{v}$ & \\
\hline
\end{tabular}

\begin{tabular}{|c|c|c|c|c|c|}
\hline \multicolumn{7}{|c|}{ TMT Changes } \\
\hline $\begin{array}{c}\text { ST } \\
\text { Depression } \\
>\mathbf{1 ~ m m}\end{array}$ & $\begin{array}{c}\text { ST } \\
\text { Elevation }\end{array}$ & $\begin{array}{c}\text { Arrhythmi } \\
\text { as }\end{array}$ & $\begin{array}{c}\text { Bundle } \\
\text { Branch } \\
\text { Block }\end{array}$ & $\begin{array}{c}\text { Exercise } \\
\text { Induced } \\
\text { U-Wave }\end{array}$ & $\begin{array}{c}\text { Total } \\
\text { Abnormal } \\
\text { TMT } \\
\text { Cases }\end{array}$ \\
\hline $\begin{array}{c}31 \\
(58.49)\end{array}$ & 12 & 02 & 6 & 2 & 53 \\
$(22.65)$ & $(3.77)$ & $(11.32)$ & $(3.77)$ & $(100)$ \\
\hline Table 4. Distribution of Abnormal TMT Changes Among \\
Patients \\
\hline
\end{tabular}

\begin{tabular}{|c|c|c|c|}
\hline \multirow{2}{*}{ Sex } & \multicolumn{2}{|c|}{ Diastolic Dysfunction } & \multirow{2}{*}{ Total, } \\
\cline { 2 - 3 } & $\begin{array}{c}\text { Abnormal, } \\
\text { N (\%) }\end{array}$ & $\begin{array}{c}\text { Normal, } \\
\text { N (\%) }\end{array}$ & \\
\hline Male & $77(50.0)$ & $77(50.0)$ & $154(100.0)$ \\
\hline Female & $54(54.5)$ & $45(45.5)$ & $99(100.0)$ \\
\hline Total & $\mathbf{1 3 1}(51.8)$ & $\mathbf{1 2 2}(48.2)$ & $\mathbf{2 5 3 ( 1 0 0 . 0 )}$ \\
\hline Table 5. Distribution of Diastolic Dysfunction of Patients \\
\hline \multicolumn{3}{|c|}{ Figures in () is percentage of row wise } \\
\hline
\end{tabular}

\begin{tabular}{|c|c|c|c|}
\hline \multirow{2}{*}{ Test for AHD } & \multicolumn{2}{|c|}{ Sex } & \multirow{2}{*}{ Total } \\
\cline { 2 - 3 } & Male & Female & \\
\hline No AHD & $54(35.1 \%)$ & $29(29.3 \%)$ & $83(32.8 \%)$ \\
\hline ECG+DD+TMT & $10(6.5 \%)$ & $11(11.1)$ & $21(8.3 \%)$ \\
\hline ECG+DD & $20(13.0 \%)$ & $14(14.1 \%)$ & $34(13.4 \%)$ \\
\hline
\end{tabular}

\begin{tabular}{|c|c|c|c|}
\hline ECG+TMT & $3(1.9 \%)$ & $3(3.0 \%)$ & $6(2.4 \%)$ \\
\hline DD+TMT & $13(8.4 \%)$ & $7(7.0 \%)$ & $20(7.9 \%)$ \\
\hline ECG & $16(10.4 \%)$ & $11(11.1 \%)$ & $27(10.7 \%)$ \\
\hline DD & $34(22.1 \%)$ & $22(22.2 \%)$ & $56(22.1 \%)$ \\
\hline TMT & $4(2.6 \%)$ & $2(2.0 \%)$ & $6(2.4 \%)$ \\
\hline Total & $154(100.0 \%)$ & $99(100.0 \%)$ & $253(100.0 \%)$ \\
\hline \multicolumn{4}{|c|}{ Table 6. Sex Wise Distribution of Asymptomatic Heart } \\
Disease Per Test \\
\hline \multicolumn{4}{|c|}{ Figures in ( ) is percentage of column wise } \\
\hline
\end{tabular}

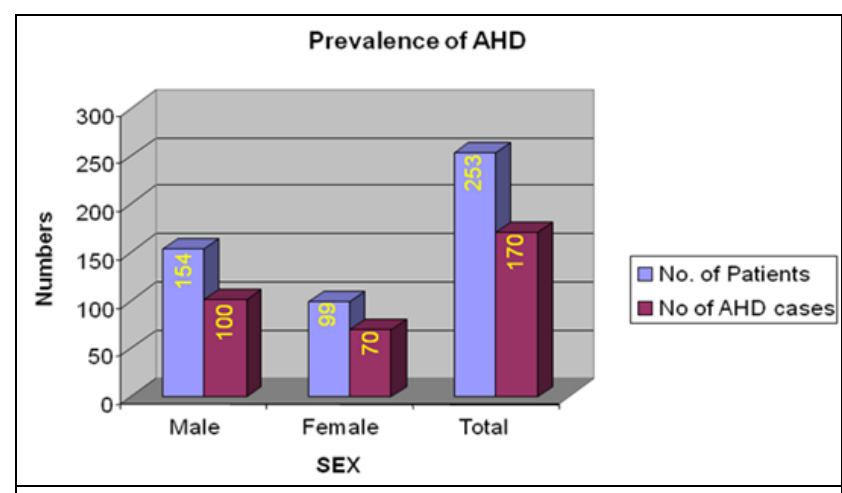

Figure 1. Prevalence of AHD. (64.93\% of AHD Patients Were Male and $70.70 \%$ Were Female.)

Over All 67.19\% of Patients Were Having AHD
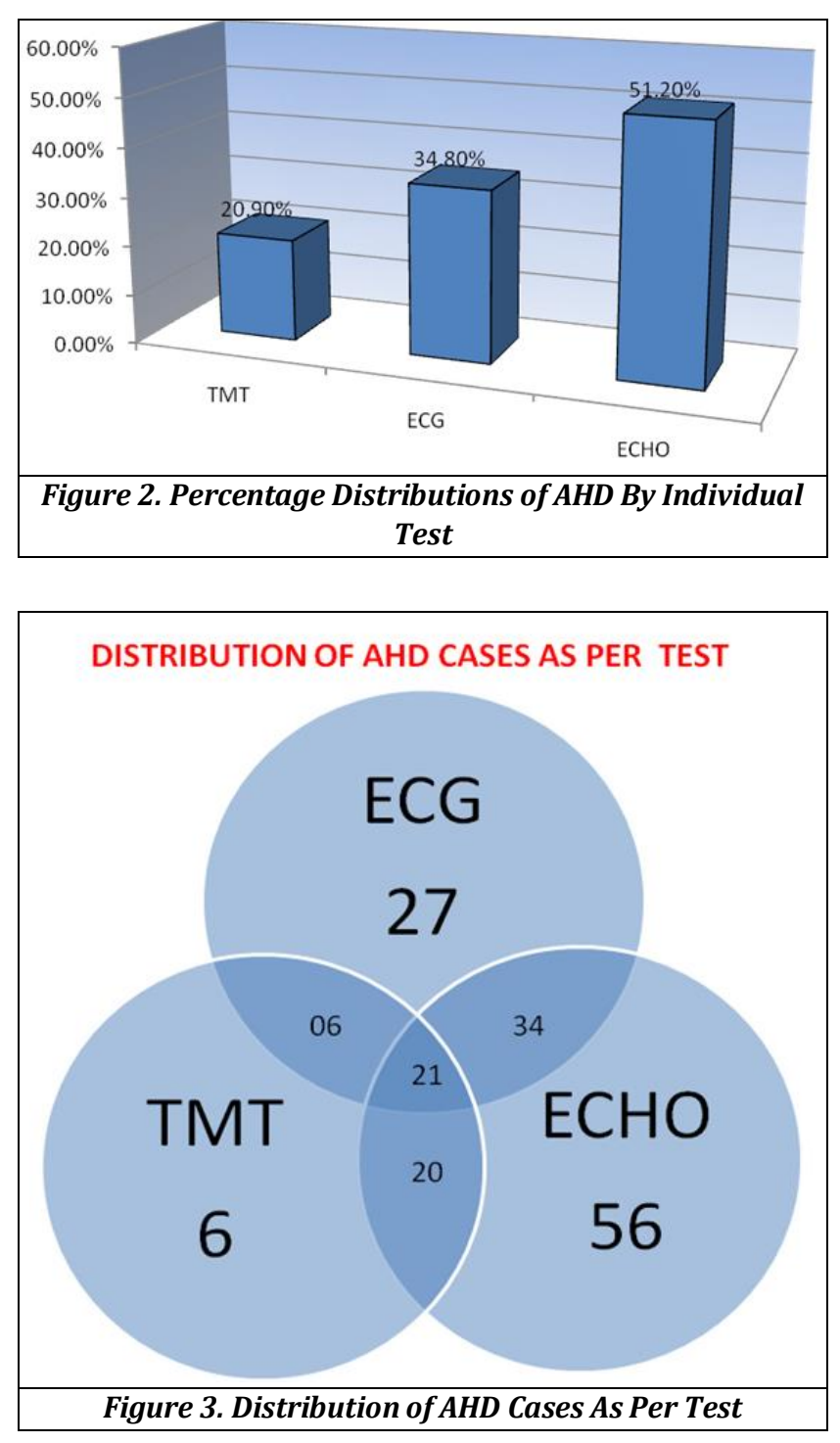


\section{DISCUSSION}

In this study there were two hundred fifty-three patients who included one hundred fifty-four males and ninety nine females. The asymptomatic heart disease (AHD) was detected in one hundred seventy patients. Several large screening studies for silent myocardial disease in diabetes have been performed demonstrating variable prevalence rates from 6.4 to $58 \% .3,4$ In this study $34.78 \%$ patients have ECG changes at rest. In a study comprising of 599 type II diabetic patients conducted by Premlatha $G$ et al found that ECG changes in asymptomatic patients was $27.87 \%$. In this study $20.94 \%$ patients had TMT positive. Baqcci et al in 2002 in screening for silent myocardial ischemia in asymptomatic type 2 diabetic patients found exercise ECG test positive for ischaemia in $19 \%$ patients. 5 Premlatha G et al showed that TMT positive test in $26.4 \%$ asymptomatic type 2 diabetic patients having resting ECG changes. ${ }^{6}$ In this study it was found TMT positive test in $10.67 \%$ asymptomatic type 2 diabetic patients having resting ECG changes. They also found TMT positive test in $11.4 \%$ asymptomatic type 2 diabetic patients having resting ECG normal. ${ }^{6}$ In this study TMT positive was found in $10.28 \%$ of asymptomatic type 2 diabetic patients having resting ECG normal. This finding was almost similar to study conducted by G Premlatha et al. ${ }^{6}$ Seshiah et $\mathrm{al}^{7}$ in a study found silent coronary ischaemia in $60 \%$ male diabetics the finding was comparable to those of separate studies conducted by Bellet et $\mathrm{al}^{8}$, Persson G et $\mathrm{al}^{9}$ and Karlefors T et al. ${ }^{10}$ It was found in this study that $64.93 \%$ male type 2 diabetic patients had AHD and this was in conformity to all those four separate studies. In this study diastolic dysfunction was found in $51.77 \%$ patients on echocardiography at rest. Bboyer $\mathrm{JK}$ et al ${ }^{11}$ found diastolic dysfunction in $63 \%$ patients using conventional echocardiography at rest. Paul Poirier et $\mathrm{al}^{3}$ found left ventricular diastolic dysfunction in $60 \%$ patients with normotensive well controlled type 2 diabetic patients. Shrestha NR et al ${ }^{12}$ found diastolic dysfunction in $60 \%$ patients in asymptomatic type 2 diabetic patients. Bajraktari et $\mathrm{al}^{13}$ Claudia $\mathrm{M}$ et $\mathrm{al}^{14}$ in 2007 stated that left ventricular diastolic dysfunction represents the earliest pre-clinical manifestation of dysfunction in asymptomatic type 2 diabetic patients. Tsujino $\mathrm{T}$ et $\mathrm{al}^{15}$ observed diastolic dysfunction in $40 \%$ of patients with diabetes mellitus \& correlates with poor glycaemic control.

In our study diastolic dysfunction was found in $51.8 \%$ of asymptomatic type 2 diabetic patients and this was almost in accordance of studies conducted by Bboyer JK et al ${ }^{12}$ Paul $P$ et al, ${ }^{3}$ Shrestha NR et al,12 Bajraktari et al ${ }^{13}$ and Tsujino $\mathrm{T}$ et al. Claudia $\mathrm{M}$, et al ${ }^{14}$ stated that diabetes might be doing asymptomatic \& causing harm to heart, even in those with no known manifestations of cardiac complication but show some degree of diastolic dysfunction early.

Majority of diastolic dysfunction was found in male in the age group of 55-64 years while in female in the age group of 45-54 years, that was 10 years earlier than male counterpart. Seshiah et al $^{7}$ in a study found silent coronary ischaemia in $60 \%$ male diabetics. It was found in our study that $64.93 \%$ male type 2 diabetic patients have AHD.

It was found in our study that $20.95 \%$ type 2 diabetic patients have AHD on treadmill test.

Claudia MV et al14 stated that diabetes might be asymptomatic \& continuously harming to heart, even in those with no known manifestation of cardiac complication but show some degree of diastolic dysfunction early. They also recommended that diastolic dysfunction screening test for cardiovascular impairment in Type 2 diabetic patients. Mishra TK et al ${ }^{16}$ stated that a asymptomatic diabetic patients have reduced left ventricular systolic \& diastolic functions as compared to healthy subjects. Left ventricular systolic \& diastolic abnormalities were correlated with the duration of diabetes. It was concluded that diabetes mellitus was the strongest independent correlate of left ventricular diastolic dysfunction.

In this study higher incidence (41\%) of AHD cases was found in male within the age group of 55-63 years and $35.71 \%$ in among female was found within the age group of 45-54 years. Singh MM et al found that the higher incidence of ischaemic heart disease in the age group of 41-60 years.

This study showed that positive correlation $(+0.287)$ with age and AHD (=0.000). The risks of AHD in the age group 6473 higher than others. In a study conducted by Meenu et al reported that there was significant correlation between duration of diabetes mellitus and coronary artery diseases. ${ }^{17}$ In this study there was a significant positive correlation observed between duration of diabetes and AHD (C.C $=0.141$, $\mathrm{p}=0.025$ ).

\section{Limitation}

As it is a hospital-based study extrapolation is not possible and this may not be representatives of patients of all socioeconomic background.

\section{CONCLUSION}

For detection of AHD, TMT and ECHO combined were more effective. Diastolic dysfunction screening test for early detection of AHD in diabetes is very important. There may be some benefit of screening by non-invasive method to diagnose AHD early in diabetes so as to prevent morbidity and mortality as CAD remains the single most common cause of death in this population. But most of the patients failed to recognize the classic symptoms of myocardial ischemia. We recommend further study involving different health institutions and follow up study.

\section{ACKNOWLEDGMENT}

We are thankful to the staff of Department of Medicine and patients who participated in the study.

\section{REFERENCES}

[1] Shapiro LM. Specific heart disease in diabetes mellitus. Br Med J 1982;284(6310):140-1.

[2] Grant PJ. Cardiovascular diseases and diabetes. In: Pickup JC, Williams G, eds. Textbook of diabetes. Vol. 2. 3rd edn. 2003:56.1-56.24.

[3] Poirier P, Bogaty P, Garneau C, et al. Diastolic dysfunction in normotensive men with wellcontrolled type 2 diabetes: importance of maneuvers in echocardiographic screening for preclinical diabetic cardiomyopathy. Diabetes Care 2001;24(1):5-10.

[4] Falcone C, Nespoli L, Geroldi D, et al. Silent myocardial ischemia in diabetic and non-diabetic patients with coronary artery disease. Int J Cardiol 2003;90(23):219-27. 
[5] Bacci S, Villella M, Villella A, et al. Screening for silent myocardial ischaemia in type 2 diabetic patients with additional atherogenic risk factor: applicability and accuracy of exercise stress test. Eur J Endocrinol 2002;147(5):649-54.

[6] Premalatha G, Anirudhan MK, Mohan V, et al. Treadmill (cardiac stress) test in the diagnosis of ischaemic heart disease in NIDDM patients: usefulness and safety. Int J Diab Dev Countries 1995;15:3-6.

[7] Seshiah V, Sundaram V, Hariharan RS, et al. Stress ECG testing in asymptomatic male diabetes. Int J Diab Dev Ctries 1983;3:52-8.

[8] Ballet S, Roman L. The exercise test in diabetic patients as studied by radio electrocardiography. Circulation 1967;36:245-54.

[9] Persson G. Exercise test in male diabetics. Acta Medica Sandinavia 1977;201(Suppl 605):7-23.

[10] Karlefors T. Exercise test in male diabetics. Acta Medica Sandinavia 1966;180(449 Suppl):19-43.

[11] Boyer JK, Thanigaraj S, Schechtman KB, et al. Prevalence of ventricular diastolic dysfunction in asymptomatic, normotensive patients with diabetes mellitus. Am J Cardiol 2004;93(7):870-5.
[12] Shrestha NR, Sharma SK, Karki P, et al. Echocardiographic evaluation of diastolic function in asymptomatic type 2 diabetes. JNMA 2009;48(173):20-3.

[13] Bajraktari G, Quinko S, Bakalli A, et al. Reduced left ventricular diastolic function in asymptomatic patients with non-insulin dependent diabetes mellitus. Med Arch 2004;58(6):220-41.

[14] Freire CM, Moura AL, Barbosa Mde M, et al. Left ventricular diastolic dysfunction in diabetes: an update. Arq Bras Endocrinol Metab 2007;51(2):16875.

[15] Tsujino T, Kawasaki D, Masuyama T. Left ventricular diastolic dysfunction in diabetic patients: pathophysiology and therapeutic implications. Am J of Cardiovasc Drugs 2006;6(4):219-30.

[16] Mishra TK, Rath PK, Mohanty NK, et al. Left ventricular systolic and diastolic dysfunction and their relationship with micro-vascular complication in normotensive asymptomatic patients with type 2 diabetes mellitus. Indian Heart J 2008;60(6):548-53.

[17] Walia M, Agarwal AK, Shah P, et al. Prevalence of coronary risk factors in non-insulin dependent (type 2) diabetics. J Assoc Physicians India 1999;47(11):1051-5. 